\title{
Curriculum Mapping of Undergraduate Medical Programmes: Recommendations for Future Directions
}

\author{
Gerda C. Botha and Adegoke O. Adefolalu
}

\section{ABSTRACT}

Background: Medical schools are expected to churn out all-rounded healthcare professionals who are competent in the prerequisite knowledge and skills necessary to address the everchanging health needs of the society. This is usually made possible through innovation and strategy, one of which involves the continuous review and renewal of all the components of existing teaching and learning plans through a blueprinting process called curriculum mapping. This blueprint allows for curriculum goals development, together with management, reviewing and organizing its contents. As curriculum mapping of medical programmes was in its infancy stage at the time of this research, this study focusses on reporting the perspectives of the curriculum leaders on future directions for curriculum mapping of undergraduate medical programmes in South Africa.

Method: Purposive sampling was used in a qualitative study among fourteen academics involved in medical curricula at all eight medical schools. Semi-structured interviews were used for data collection, and analysis was done by thematic analysis.

Results: Curriculum planners have specific expectations of curriculum mapping of undergraduate programmes as a possible future strategy to drive curriculum review and renewal in the country. Although some agreement exists about the characteristic features, any mapping platform created should meet the specific institutional requirements that will address their challenges.

Conclusion: Finally, a national mandate from the authorities will be required to achieve curriculum benchmarking and collaboration amongst the medical schools to standardize undergraduate medical programme outcomes.

Keywords: Curriculum mapping, mapping platform, medical school, medical students, undergraduate programme.
Published Online: November 03, 2021

ISSN: $2736-4534$

DOI : 10.24018/ejedu.2021.2.6.174

\section{G. C. Botha}

School of Medicine, Sefako Makgatho Health Sciences University, Pretoria. South Africa.

(e-mail: gerda.botha@smu.ac.za)

A. O. Adefolalu*

School of Medicine, Sefako Makgatho Health Sciences University, Pretoria. South Africa.

(e-mail: adegoke.adefolalu@smu.ac.za)

*Corresponding Author

\section{INTRODUCTION}

The curriculum map provides a visual analytic tool which displays the essential features of the curriculum in a clear and succinct manner, and makes evident the need for strategic decisions, which in turn can lead to improvement of the defined programme outcomes [1]-[3]. Furthermore, the curriculum map is highly instrumental in the identification of the core curriculum of any medical programme, thereby enabling the reduction of any unplanned duplications, revealing gaps within the curriculum contents at the same time assist in the alignment of programme outcomes across the entire curriculum [1], [2]. Traditionally, much of the information in a curriculum were managed by various academics in isolation from one another, but a curriculum map, however, brings together the different elements in such a way that the overall picture of the medical programme, as well as the connections between contents, can be rapidly visualized and appraised by any of the stakeholders [3].

There is growing awareness among medical educators of the sophisticated electronic mapping as a platform to showcase the medical curriculum to both insiders and outsiders, this realization stemmed from the obvious limitations of the paper-based graphical representation of the curriculum which has been in use for many years [1]. Since the electronic mapping platform allows for multi-dimensional mapping of the curriculum with a series of matrices [4], which enables the linking of complex, student-centered competencies with course-specific and well-defined objectives, it is increasingly being used to model, track and report on contemporary curricula by several medical institutions across the globe [5]-[7]. The electronic system works by simplifying and abstracting curricular data to show important patterns and relationships for the purposes of curriculum management, analysis, and reporting [4], [5], [8]. Therefore, the computer-based curriculum map has been identified as a tool that will allow both staff and students to 
understand the planned progression and complex relationships between various elements in the curriculum by diagramming these various relationships in such a way anyone could visualize the map within a short period of time and grasp the overall picture of the entire curriculum. In other words, this is often referred to as having a "bird eye" view of the curriculum by visualizing the map [9]. According to the literature, the requirements for the successful implementation of curriculum mapping in medical schools include the provision of information technology support, academics buyin and the presence of supportive leadership to take on the task [1].

We reported on the state of curriculum mapping among South African medical schools in an earlier article which showed that none of the nation's medical schools had a comprehensive electronic mapping platform prior to 2015 [10]. Since a relatively small number of institutions undertake medical training and the potential for economies of scale if these institutions work together can result in optimal training of medical practitioners for the country. Considering the above, there is a need for research to explore and report on perspectives on what key stakeholders in curriculum planning and development of undergraduate medical education in South Africa expect of a mapping platform after it has been fully developed. The current study therefore reports on the curriculum leaders' perspectives of the future direction for the mapping of undergraduate medical curricula in the country with a view to offering recommendations specifically for the South African context.

\section{Methodology}

\section{A. Research Design, Study Setting and Sampling}

This was a descriptive, explorative, qualitative study that employed purposive sampling in recruiting academics involved in medical education curricula at all the eight South African medical schools in 2015. Fourteen people in total, including the designated academic manager at the respective medical school and, in some cases, also the dean, agreed to participate. Ethical clearance was obtained from the Stellenbosch University's Health Research Ethics Committee (S15/05/123). Informed consent was obtained from all the participants and the principle of anonymity and confidentiality was adhered to throughout the research process. Permission to conduct the study was also obtained from the deans of medical schools.

\section{B. Data Collection Methods}

Data was generated through semi-structured interviews with a checklist of probing questions that was developed together with the interview schedule and used flexibly as a guide during the interview process. Some of the interviews were conducted in Afrikaans language and needed to be translated. One institution provided a team of interviewees which resulted in a group discussion with five people. The interviews lasted between 43 and 77 minutes and were conducted by the same person and audio recorded.
TABLE I1: PARTICIPANTS REPRESENTATION ACCORDING TO UNIVERSITY

\begin{tabular}{cccccccccc}
\hline University & U1 & U2 & U3 & U4 & U5 & U6 & U7 & U8 & Total \\
\hline $\begin{array}{c}\text { Number of } \\
\text { participants }\end{array}$ & 1 & 1 & 1 & 5 & 1 & 1 & 2 & 2 & 14 \\
\hline
\end{tabular}

\section{Data Analysis}

Data analysis began immediately after data collection commenced and continued over a period of months to allow for data immersion. The audio recordings were listened to several times to allow for data familiarization, and the transcriptions were also read repeatedly. Translation from Afrikaans language to English language was done where participants spoke in Afrikaans; the translated transcripts were reviewed by an external coder who is fluent in both Afrikaans and English languages. Thematic analysis was conducted through an inductive and multistep iterative approach [11] and all the coding generated by the researcher analyzing the data was subsequently confirmed by an external coder to ensure credibility and trustworthiness of the research process. The summary of the qualitative data was presented in themes under the results section below.

\section{RESULTS}

Five main themes emerged from the data regarding a possible future for implementing curriculum mapping in South Africa, namely, preferred method of mapping; expectations of a mapping platform; elements to be included within the platform; stakeholders and stakeholder access; and institutional requirements for successful implementation. To illustrate these categories, selected interview excerpts that clearly represent the theme being discussed and the views of the study participants are presented below.

\section{A. Preferred Method of Mapping}

The preferred method of mapping differed amongst the institutions and was linked to five specific factors, namely, personal preference, accreditation requirements, value and ease of use and cost. Five institutions indicated that they would prefer an electronic platform that has a track record of being useful (for quality assurance and accreditation) and user-friendly (easy and uncomplicated to use) and can reflect the unique organizational structure of the curriculum at the institution (allowing for uniqueness). This is well emphasized in the response of one of the participants highlighted below.

Integration becomes visible, now especially with all the modules that we so far mapped because you have a searchable database. You see the whole spiral. It is there within a few seconds and that was not apparent with the manual system we had before as all was separate in various documents. So, the benefit is that it is on one database, and it is searchable. It is accessible from anywhere, so it is not locked in a cupboard (laugh) it is not in various cupboards (laugh)... I would say it is alive, it is all together. When you have something like this electronic platform, it is all there, it is very visible, it is very easy to change, and it is institutional, it belongs to us all.... (P2 from U7). 
When prompted as to why specifically an electronic mapping platform, three of the five institutions who desired it expressed their motivation in emotional terms (to avoid embarrassment, to evoke enthusiasm for curriculum review) as well as in functional terms (for transparency, for alignment, for educational understanding, for curriculum review and reform):

I have a heartfelt desire for it, it is indispensable for the times we live in. I am embarrassed being the manager for 14 years and not knowing what is going on, having to sit down and scrutinise various guides... my basic need for a map is to know exactly what happens where. And for the students to show them what will happen over the next years ... and you need to show the curriculum to new registrars, so they know what to teach; let us say students that arrive with them in the third year for a clinical rotation, to show them what these students have done before, the levels also... (translated...P1 from U1).

Two institutions indicated that they preferred uncomplicated, paper-based mapping, because of the potential complexities involved in electronic mapping:

Curriculum mapping is a change management project and brilliant process but poses many challenges. I like simple, non-complicated. If you could map on a piece of flipchart paper... just straight forward. My experience has been that there is all sort of maps around, but those tools only work if the person putting the data in is very clear about the data... I do not think that you can map initially on an electronic tool, you have to map on paper. When your paper map is clear you can do it with a tool and then if you press it everything else will pop up. The problem with electronic tools is you are limited by the screen; you cannot work on something that is not on the screen, and if you keep pressing the button in the end you have 17 screens open... and then you sit to work backwards, and I really struggle with that... (sigh) (P1 from U2).

One institution did not specify the nature or format of a mapping instrument, but was yet again specific about the tool being of value (for instance to replace existing evaluation questionnaires as template for quality assurance) and easy to use:

I think it will be valuable to develop such a tool. It depends on how user friendly it is. It should contribute to quality enhancement... so if you have a mechanism to do that, it will be very valuable. I do not know how involved you are with HPCSA accreditation, but that report of over 100 pages is really not user-friendly, even the new template is not yet an optimal tool to use. So, I think if a map is user-friendly, it can even be used by HPCSA, to make their task easier. Although the content will be different, if the template is the same it entails all the components which all of us have to address. I am very much in favour for something like that. (Translated P1 from U3).
Some institutions indicated caution regarding the costs involved, especially financial implications, as this seemed to be a determining factor in obtaining a sophisticated mapping platform.

I think the biggest challenge for the map will be the data input, the people needed to create the map, the technical expertise and then of course the cost. I have seen it is not a simple task to build the map and it also is not cheap... (translated P1 from U1)

I don't know if they (management) will think mapping is important if they have to spend money, they might think it is unnecessary because one can get the information currently if you really want it... you can ask a head of a department or look in a book... (translated P2 from U8).

\section{B. Expectations of Institutions for a Mapping Platform:}

Under the second theme, the various medical institutions had very specific expectations of a curriculum mapping platform. In terms of categorising these expectations, four main functions for the curriculum map emerged, these are categorised into four following sub-themes i.e., Transparency and sharing of a vision for the curriculum; Curriculum review and renewal; Collaboration, benchmarking, and accreditation; and providing data for administration, research purposes.

\section{Transparency and sharing of a vision for the curriculum}

Some participants opined that mapping should provide for transparency and for a shared vision amongst different stakeholders within the institution, especially those from different disciplines. In addition to this, they also asserted that mapping should be seen as having the potential to overcome the current challenges experienced by medical schools regarding integrated curricula, as illustrated in the following quotes:

It has the potential to bring together people, to build the bridges between silos and provide for clear articulation backwards and forwards for different parts of the programme... (P1 from U2)

Providing all stakeholders with the full picture will enable them to work with the end in mind; and this result in a more holistic and efficient work approach... (translated P1 from U3).

\section{Curriculum Review and Renewal}

Another expectation was that curriculum mapping should be used as a tool to facilitate curriculum review and renewal as part of an ongoing curriculum management process. It was felt that this would result in continuous quality improvement and innovation.

To use it as a curriculum management and review tool in constant reflection on a curriculum, this should very much be a living document; something that is continuously affected on and evolve in continuously 


\section{reviewing the curriculum... (P1 from U6)}

It gives you the opportunity to make the review at the time when you are not required to do it as part of a formal review; it gives you an on-going review process... (P2 from U7).

Participants emphasized that mapping should make it easier to find 'gaps' and detect duplications or redundant contents within the curriculum. The participants opined that curriculum review should assist in defining core content and reduce information overload:

To use it for gap analysis and blue-printing exercises to see where things were skipped or has fallen off, or where unnecessary duplication is taking place, to see where things are going well and where more work is needed... (translated P1 from U1).

The biggest plus of having a curriculum map is that the students' anxieties about what they have to learn will go away, because we drive students to insanity by producing 700 conditions for seven weeks... (P1 from $\mathrm{U} 2)$.

The data also revealed that participants expect the mapping platform to assist the institutions in aligning level of learning, learning outcomes and how assessments are done across the whole medical programme. Such alignment is necessary in the context of medical programme where several modules are taught by different departments:

Align learning and assessments for each module with module specific objectives and programme exit level outcomes... (translated P1 from U3)

The alignment and integration are the main issue I would like to see addressed, there is lots of things that gets repeated, the students say there is duplication and contradictions, they say we teach them one thing and another discipline teach them different, so it will help to see we are in line, that the content is in line... (translated $\mathrm{P} 2$ from U8)

\section{Collaboration, benchmarking, and accreditation}

According to the participants, curriculum mapping should be able to facilitate accreditation, benchmarking, and collaboration for standardisation, especially when it is linked to an existing national framework.

I think one of the advantages at professional board level if everybody maps, is simplifying the task of accreditation, you know, I think the map can be used to complete the self-assessment questionnaire... (translated $\mathrm{P} 1$ from U1)

I think one should be guided by the HPCSA document on competencies, one maybe should consider how you can incorporate these competencies applicable to your curriculum as I would like to link the frameworks with each other... (translated P1 from U3)
Participants saw collaboration with other medical schools in the country as potentially beneficial as far as it is providing guidelines for quality and standardise outcomes, and as it can assist in reaching a national consensus regarding the core content at undergraduate level:

Currently we have a variety of programmes, but the burden of disease seems to be the same throughout and the quality of what a doctor should be like, is national. So, in that way I think institutions need to sit together and look at curricula in terms of standardisation of national outcomes... (P1 from U6)

I think one can learn from each other, none of us are really experts in education and when in our department we have to sit and formulate outcomes it comes out completely dissimilar, some say they (undergraduate) MUST have this, others say, NO, it is highly specialised; so I think it will help to have a look at what other institutions have, you have a bigger pool to look at... if you can click on a map... currently it is very difficult to obtain...(translated P2 from U8)

However, although institutions expected a mapping platform to assist with benchmarking, accreditation, and possible future collaboration, institutions were cautious about sharing the same platform given the fact that curricula are unique:

We have a difference in focus at different universities; the problem we have here, we seem to have different spectacles looking at medical training in South Africa and when you have different outlooks it becomes difficult for you to have a common ground for a meeting... (P1 from U5)

Universities have different histories and different designs, and where they are coming from is different. LOOOP (Learning Opportunities, Objectives and Outcome Platform) was adjusted for our specific context, it will be problematic to share it just as it is; remember the platform is also linked to organisational components such as the timetables and specific lecturers. In Germany they even have patients. The sharing of the academic information is possible when comparing the content part but not the organisation. (P2 from U7)

\section{Providing data for various administrative and research purposes}

The fourth sub-theme under the expectations of curriculum leaders on mapping platform revealed that the participants envisaged that mapping should provide data that would aid in making some administration decisions; facilitate educational research; facilitate students' placement and students' progress tracking and faculty development purposes.

The map will help the manager to know which departments teach in integrated modules and make decisions regarding subsidy allocations... (translated P1 
from U1)

Curriculum mapping can provide statistics regarding the core curriculum. We are having this debate about teaching the core curriculum; statistical analysis will assist to pull that numbers out of a map, or out of a database. A map can assist education innovation converted to a research project with a very specific question; you actually can get the information that you need......Data that is properly presented will create credibility. In the end if you got your data properly you could present it properly, it is credible, and credibility is a huge part of change management... (P1 from U2)

One of the participants emphasised the challenge of placement and progression of students in various tracks with different educational backgrounds and experiences. The participants hoped mapping would assist in making decision on where to place students within the medical programme if such students transfer to the institution from another:

The map should show for instance, would it be possible to take students directly into second year; or show if the curriculum change substantially, will it still be appropriate for students returning from Cuba to come into our five and a half year? The map should be able to track students in different tracks (fast or highlevel track, research track, dual track, parallel curriculum) The map should assist us to analyse student progress, especially through formative assessments, picking up on struggling students and providing support... (P2 from U4)

\section{Elements to be Reflected in an Electronic Mapping Platform}

The elements on which all participants agreed should be included are Content and learning outcomes; Learning and teaching strategies; Assessment strategies; as well as Third party outcomes frameworks, taxonomies, and vocabularies.

1) Content in terms of learning outcomes and objectives

All institutions indicated the importance of reflecting on the unique structure of the curriculum. Some articulated it explicitly while others referred to the different year levels, phases or semesters in a spiral, and progression between these years, phases, or semesters. Some of the institutions also emphasised content explicitly by wanting the map to show themes and topics as they spiral through the curriculum. All institutions wanted objectives, outcomes, or competencies to be specified in the map, such as exit level outcomes for the programme as well as module outcomes and objectives for topics within the modules or units of learning. The participants were particular about the ability of the map to show breadth and depth of outcomes:

It is NOT important to put the date and time and lecturer detail, but rather exactly what the content was and to what depth it was taught and how we have addressed it at first year, at what level, what contents and so progressively up the years for all the years... (P1 from U4)
Because one of the biggest challenges of mapping is not actually the clinical presentations or the list of conditions... it is the depth to which their knowledge needs to be taken... (P1 from U2)

\section{2) Learning strategies, methods, and platforms}

All institutions wanted learning and teaching strategies, lectures, tutorials, seminars, practical and ward rounds to be displayed within the mapping tool. They emphasised the importance of including the platform and/or venue where teaching and learning is to take place, for example ambulatory setting, clinic, ward, outreach facility, rural hospital, tertiary hospital, rehab site, hospice, laboratories, and dissection rooms. Some institutions preferred a link to the e-leaning management system and resources. One institution would prefer to link policies such as the policy on needlestick injuries, as a key issue in the South African health system where HIV/AIDS is still extremely prevalent. One institution indicated the possibility for the mapping platform to potentially map patients in the future.

You can check the availability of patients, to map the number of beds so students can book... (P2 from U7)

\section{3) Assessment strategies}

The need for the map to be able to show alignment of assessments with the specified outcomes, as well as competencies, was also expressed. Participants felt that assessment criteria, strategies and methods and details about tasks should be included in the maps. One institution indicated the inclusion of assessment rubrics, and another indicated a link to a database with previous assessment papers.

It takes a huge amount of time to set a MCQ... so why do we have seven bunches of people around the country... all doing what others do... most of the questions should be free to share amongst each other and a map can assist with that. (P2 from U4)

\section{4) Third party outcomes frameworks, taxonomies, and vocabularies}

A key component of a curriculum map is the need for a clear taxonomy or framework. Some institutions mentioned the HPCSA-adopted version of the CanMeds model, while one institution mentioned SAQA NQF level descriptors, Bloom's taxonomy for knowledge outcomes and Miller's pyramid for skills. The vocabularies described by one institution included MESH (Medical Subject Headings) terms. Other institutions indicated utilising the HPCSA logbook for interns.

\section{Stakeholders and Stakeholder Access}

Ultimately the utility of a curriculum map relies on the extent to which it meets the needs of those who will use it and is accessible to them. The stakeholders that should have access with or without specified limitations to the curriculum mapping platform include curriculum planners, all academics regardless of level and representation in committees, support staff, students, authorities, and even visitors and the public. 
It is a matter of giving access to someone, we can create a password to make certain information available, it is just a matter of getting the permission or whether to authorise... perhaps you could have a limited view for the outsiders... (P1 from U7)

\section{E. Institutional Requirements for Successful Implementation}

The identified requirements for a mapping process to be successfully implemented resort around two main issues, namely, mandate/buy-in and resources. It seems that, without these requirements being met, mapping will not be regarded as a priority to engage in for the medical schools.

You need a mandate that this is actually something that you have to have because people are in different places, depending on the change-readiness of the group, you may get completely stalled because some disciplines are not interested ... It is very difficult to get people to look at something if they do not understand what they are meant to do with it. It is not valued in the university; nobody cares if there is a map or no map. You do not get a promotion for it; you don't win a prize and you don't get a medal... (P1 from U2)

The institution is to appoint a champion and driver with good negotiation skills and the ability to bring people together and to establish a small team with an IT expert and academics at the appropriate levels... (P1 from U2)

\section{DiscUSSION}

It is evident from this study that the various institutions have preference for a certain kind of mapping tool based on their perceptions. As reported in literature, paper-based maps have been used successfully to display relationships between curriculum elements in tabular format, while the motivation for electronic platforms is formulated around sophistication [5], [9], [12]-[14]. Five institutions indicated a preference for a sophisticated electronic platform because they felt it would allow for a searchable database in one place which, once developed, would provide quick access to all information, and assist in curriculum review and management (value). Sophisticated mapping platforms, however, come at a cost and institutions will need finance and the expertise to develop a platform and maintain it. In the current financial climate, this might be a challenge for some institutions in South Africa. It seems that the final decision with regards to a mapping platform will be determined by weighing up the value added to curriculum management against the financial investment institutions will have to make to develop and maintain the platform.

Participants had a variety of expectations of curriculum mapping. It could be argued that these expectations point to the type of sophistication only an electronic mapping platform that is linked with third party vocabularies and outcomes taxonomies, can provide. Previous studies indicate that these expectations can be met if the platform is planned and developed according to the needs of the stakeholders [1], if the stakeholders are involved in the planning, and if the platform allows for some flexibility and ongoing development as the needs change [3], [6]-[8], [12]-[15].

Using mapping for benchmarking and accreditation purposes implies stakeholders from the various institutions need to collaborate to define the features and functions of such a map and decide as a group on the specific outcome framework and vocabularies. If these are not available, they would have to be created for the South African context and this might best be undertaken soon before many of the institutions fully developed their unique mapping platforms. This could hinder the possibility of having uniformed features and functions of mapping among the medical schools, as any of the schools could decide to map using MeSH terms or ICD10 code terminologies.

The results of this study show that four institutions, representing just half of the institution involved in the study, recommend using the HPCSA-adopted CanMeds competencies as a framework to enable benchmarking. This result suggests a challenge in terms of achieving a national approach to curriculum mapping. Additional to that, curriculum mapping platforms might include all the mentioned elements, but the structure and the design of the curriculum might differ (e.g., five-year vs. six-year, integrated vs. traditional), and therefore institutional maps will be different. The benefit of all the institutions mapping the same basic elements is that it will be easy to see where institutions can collaborate more (e.g., share clinical training platforms) or to perform benchmarking exercises (e.g., crossreference outcomes for anaesthesiology amongst participating institutions). As some institutions expressed the need for a single exit level standard and possibly MCQ examination, assessment questions might in the future need to be mapped specifically. While taxonomies such as Bloom's can determine alignment and progression [15]-[16], this expectation immediately raises issues pertaining to institutions having access to each other's databank of MCQs while limiting student access.

In this study, participants identified students, academic staff, and curriculum planners as important stakeholders in the mapping process and as users of a mapping platform and not as an element to be mapped. Identified stakeholders and users are like those described in literature [1]. The frequency and use of the map will be determined by the needs of the user and the questions he/she wants to be answered. As has been indicated before, stakeholders have varying needs of the map. In the case of assessment questions and results, password protected access is indicated. Students will need to understand that curriculum mapping is not to be confused with an e-learning system.

The requirements for successful mapping mentioned by the participants in this study and summarized above corresponds with what is found in literature [1], [3], [5], [7]-[9], [12]-[17]. Full institutional support (management, finance, human resources, IT, faculty development etc.) will be needed for institutions offering medical training in South Africa to successfully implement curriculum mapping. One institution indicated that support is often forthcoming when curriculum planners can show it is a priority within the national context, or when it can be driven as a research project which contributes to a scholarship footprint. If mapping is to be 
taken seriously at all institutions in South Africa, it will need to be put on the national agenda, either by the HPCSA undergraduate committee or through the Committee of Medical Deans.

\section{CONCLUSION}

In conclusion, there is no doubt that curriculum mapping of undergraduate medical programmes in South Africa remains a possible strategy that could be used to drive curricula review and renewal within the existing medical schools in the country. As the above is being carried out, it is important to bear in mind what the stakeholders' recommendations are in the current study, especially the need for curriculum leaders and other responsible persons at each medical school to ensure that mapping platform created meets the specific institutional requirements that will address the various challenges associated with curriculum mapping in that school, while at the same time portraying the unique structure of the medical curriculum itself. Finally, a national mandate from the appropriate authorities will be required to achieve curriculum benchmarking and collaboration amongst medical schools. This move would ensure some form of standardization and probably uniformed graduate outcomeattributes of all the undergraduate medical programmes in South Africa. Additional research about the impact of curriculum mapping of undergraduate medical programmes in South Africa in the national context is indicated.

\section{ACKNOWLEDGMENT}

The authors would like to thank Prof Susan van Schalkwyk and Prof Ina Treadwell for their assistance and Dr Yolinda Uys in confirming analytical coding. The time commitment and valuable information shared by the participants are well appreciated.

\section{REFERENCES}

[1] R. M. Harden, "AMEE Guide no. 21: Curriculum mapping: A tool for transparent and authentic teaching and learning," Medical Teacher vol. 23, no 2, pp. 123-137, 2001.

[2] D. Prideaux, "ABC of learning and teaching in medicine: Curriculum design," British Medical Journal, vol. 326, pp. 268-270, 2003.

[3] C. Steketee, (2015) "Prudentia: A medical school's solution to curriculum mapping and curriculum management," Journal of University Teaching and Learning Practice, [Online]. vol. 12, no. 4, Available: http://ro.uow.edu.au/jutlp/vol12/iss4/9.

[4] W. E. Blaum, A. Jarczweski, F. Balzer, P. Stötzner and O. Ahlers, (2013). "Towards Web 3.0: taxonomies and ontologies for medical education -- a systematic review," GMS Z Med Ausbild [Online]. vol. 30, no. 1, pp. Doc13. Available:

http://europepmc.org/article/PMC/3589681.

[5] R. Ellaway, S. Albright, V. Smothers, T. Cameron and T. Willett, "Curriculum inventory: Modelling, sharing, and comparing medical education programs," Medical Teacher vol. 36, no. 3, pp. 208-215, Feb 2014.

[6] F. Balzer, A. Bietenbeck, C. Spies, M. Dittmar, L. Lehmann, F. Sughiharto and O. Ahlers, "How we avoid patient shortage with an integrated analysis of learning objectives and clinical data during development of undergraduate medical curricula," Medical Teacher vol. 37, no. 6, pp. 533-537, 2015. Epub 2014.

[7] F. Balzer, W. E. Hautz, C. Spies, A. Bietenbeck, M. Dittmar, F. Sugiharto, L. Lehmann, D. Eisenmann, F. Bubser, M. Stieg, S. Hanfler, W. Georg, A. Tekian and O. Ahlers, "Development and alignment of undergraduate medical curricula in a web-based, dynamic Learning opportunities, objectives, and outcome platform (LOOOP). Early online version," Medical Teacher vol. 38, no. 4, pp. 369-377, 2016.

[8] M. H. Davis and R. M. Harden, "Planning and implementing an undergraduate medical curriculum: The lessons learned," Medical Teacher vol. 25, no. 6, pp. 596-608, 2003,

[9] M. Britton, N. Letassy, M. S. Medina and N. Er, (2008). "A curriculum review and mapping process supported by an electronic database system," American Journal of Pharmaceutical Education [Online]. vol. 72 , no. 5 , pp. 99. Available:

http://www.ncbi.nlm.nih.gov/pmc/articles/PMC2630156.

[10] G. C. Botha and A. O. Adefolalu. (2020). "Status of Curriculum Mapping of Undergraduate Medical Programmes in South Africa," European Journal of Medical and Health Sciences [Online], vol. 2, no. 3. Available: https://ejmed.org/index.php/ejmed/article/view/284.

[11] V. Braun and V. Clarke, "Using thematic analysis in psychology," Qualitative Research in Psychology vol. 3, no. 2, pp. 77-101, 2006.

[12] R. Ellaway, P. Evans, J. Mckillop, H. Cameron, J. Morrison, H. Mckenzie and S. Guild, "Cross-referencing the Scottish doctor and tomorrow's doctors learning outcome frameworks," Medical Teacher vol. 29, no. 7, pp. 630-635, 2007.

[13] E. G. Watson, P. J. Moloney, S. M. Toohey, C. S. Hughes, S. L. Mobbs, J. B. Leeper and H. P. McNeil, "Development of eMed: A comprehensive, modular curriculum-management system," Academic Medicine vol. 82, no. 4, pp. 351-360, 2007.

[14] T. G. Willett, "Current status of curriculum mapping in Canada and the UK," Medical Education vol. 42, no. 8, pp. 786-793, 2008.

[15] R. M. Harden, "Learning outcomes as a tool to assess progression," Medical Teacher vol. 29, no. 7, pp. 678-682, 2007.

[16] D. Prideaux, "Curriculum development in medical education: From acronyms to dynamism," Teaching and Teacher Education vol. 23, no. 3, pp. 294-302, 2007.

[17] R. M. Harden and I. R. Hart, "An international virtual medical school (IVIMEDS): The future for medical education?" Medical Teacher vol. 24, no. 3, pp. 262-267, 2002.

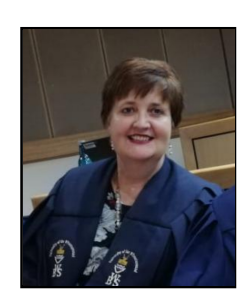

Ms. Gerda C. Botha, MA (Counseling Psych), MPhil (HSE) is the Programme Leader of the Practice of Medicine integrated module of the MBChB curriculum at Sefako Makgatho Health Sciences University, South Africa. She has extensive experience in curriculum design and academic planning of undergraduate medical curriculum. She is a member of the university's Academic Planning committee (APCDC) and the Curriculum Development Committee (CDC). She is also seasoned in the design and developments of decentralized platforms for training and early patient exposure for undergraduate medical students. Her research interests are mainly in health professional education, focusing on curriculum mapping, module integration in medical education, teaching and assessment modalities, and inter-professional medical education.

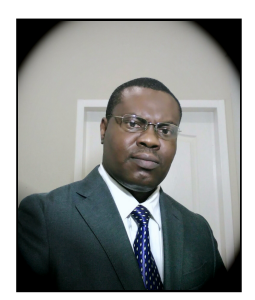

Dr. Adegoke O. Adefolalu, $M B C h B, D i p H I V$ Man (SA), MPH, PhD, FRSPH is at the School of Medicine at Sefako Makgatho Health Sciences University, South Africa, where he teaches medical students Epidemiology and Research Methods within the Practice of Medicine programme of the MBCHB course. A Public Health physician with research interests in Clinical Epidemiology, Health behavior and Health determinants, HIV/AIDS, and Health Systems. An astute health advocate, Dr Adefolalu is also involved in mentorship and participates actively in staff development. 